\title{
Research on Internal Governance of Accounting Firms in China Jihui Sun ${ }^{1, a^{*}}$, Jia Gao ${ }^{1, b}$ and Jianxin Sun ${ }^{2, c}$ \\ ${ }^{1}$ School of Economics and Management, Dalian University, Dalian, China \\ ${ }^{2}$ School of Xinhua international business, Liaoning University, Shenyang, China \\ adlsunjihui@163.com, ${ }^{b} 695961636 @ q q . c o m,{ }^{c}$ sunjianxin929@sina.com \\ * The corresponding author
}

Keywords: Accounting firm; Internal governance; Internal control

\begin{abstract}
This paper is based on the basic concept of internal governance, through summing up the characteristics of domestic construction firm, proposed the existence of internal governance of accounting firms and the problems and propose countermeasures by the theoretical framework, from the decision-making and supervision mechanism construction, moral construction, cultural construction, the establishment of the system of risk control and benefit distribution and improve the internal governance of accounting firms. So the accounting firms become bigger and stronger
\end{abstract}

\section{The Meaning of internal Governance of Accounting Firms}

The Concept of Internal Governance. Governance is the system of setting up enterprise goals, deciding enterprise behavior, managing and controlling enterprise's corresponding business activities. Its own function is mainly how to rationally allocate responsibilities, obligations and profits. Therefore, corporate governance is the summary of how to balance the distribution of interest among stakeholders, how to share the benefits between different subjects and the magnitude of risk. The accounting firm for the internal governance, in fact, is a series of institutional arrangements, including the arrangement of accounting firms. Firms should consider how to allocate power, how to carry out effective supervision and how to manage to make risk reduction.

The Content and Characteristics of Internal Governance. First, the concept needs to be controlled. The idea is the embodiment of the overall culture of accountants. Therefore, the accounting firm should deal with all staff, strengthen their sense of responsibility, be responsible to the public, adhere to the principle of survival. Second, policies need to be controlled. The formulation of the corresponding control policy needs to be combined with the legal system and the actual situation. Third, procedures need to be controlled. The control program should include: appointment level, unit audit affairs staff quality level of the dispatch list. In order to make auditors and the quality of work to a fairly high level, the accounting firm's heads and partners should be different levels of guidance and supervision of subordinates. Last, set up independent control departments within the firm. The main function of establishing a separate department in accounting firms is to maintain and manage customer relationship.

Internal governance characteristics. First of all, the manpower in the accounting firm is its most special initiative. In the daily operation of the firm, the wage accounts for a large part of the expenditure of the accounting firm, and the added value of labor is greater. That is, human resources are the main source of profit. Secondly, the accounting firm should take social responsibility as the priority, full account of the interests of the public, and make reasonable judgments through their own efforts. Finally, the accounting firm governance structure includes the relevant rights holder, CPA or practitioner. The board of directors often entrusts the agent to win the profit for the enterprise, and uses the certain bonus to stimulate the agent.

The significance of internal governance of accounting firms. As to promote the stable development of China's economy and independent enterprise, the enterprise's economic profit showed a positive growth effect, accounting firms in the national economy cannot be overlooked. And the domestic market is not mature, the industry competition intensifies, we can see that more perfect internal governance is essential for accounting firms. When the accounting firm 
implements internal governance better, it can strengthen the risk prevention consciousness of the firm, improve the quality of the practice, and make the firm grow healthily.

\section{The Internal Governance Problems of Accounting Firms in China}

The Mechanism of Decision-making and Supervision is Unsound. First of all, ownership structure directly affects the status of decision-making, minority shareholders occupy a large proportion of the shares, which led to the phenomenon of large shareholders decision-making, thereby reducing the scientific decision. The board of supervisors of the shareholders' meeting, the board of directors and some companies do not clearly define their respective responsibilities. Secondly, the audit department inside the firm is not entirely independent, so it can not make the supervision and management functions completely transparent, make the internal audit process is not correct, resulting in incorrect audit results.

The Level of Professional Ethics Needs to be Improved. Because of financial fraud, the capital market was greatly impacted. For example, Edmond branch listed companies ignore national relevant laws and regulations to implement financial fraud and hinder the capital market. In particular, some small and medium accounting firms, accounting for more than $80 \%$ of the more than 8000 firms that have been established in China, are small accounting firms. In terms of income, small accounting firms are under great pressure. Therefore, in order to improve performance and increase profits, they will not consider accounting professional ethics so as to condone some illegal phenomena. In order to obtain extra income, certified public accountants, even if there are some moral problems, also provide opinions and suggestions for the enterprise customers. The internal governance of the company is mainly the practice of quality control and risk prevention. How to establish the quality control system, we should pay attention to social public trust, improve the transparency of practice.

The Corporate Culture of CPA Firms needs to be Developed. Corporate culture is a kind of culture that reflects the special aspects of the enterprise, the expectation of the enterprise and the social responsibility. PWC's corporate culture has one characteristic: "quality first". In addition, the firm attaches great importance to the careful handling of the partnership. In Ernst \& Young's corporate culture, "people first" stands out. KPMG has a very democratic culture. Its flexible working hours system for female employees makes they can handle personal affairs flexible. Adaptation cultural differences, clear division of labor responsibility and fair and impartial evaluation of employees are all our accounting firms need to learn. Many of China's accounting firms are not aware of the importance of corporate culture, so they lack the stable corporate culture.

Lack of Perfect Risk Control System. The business risk becomes bigger, and the corresponding audit risk becomes bigger. The internal risk control of accounting firms is weak, and most accounting firms do not establish an adaptive risk control system. In the United States, there were 181 lawsuits against the CPA in 1960 to 1972, and from 1973 to 1985 occurred in 291, after 1985, aimed at CPA litigation more, the amount of compensation is more and more big, the risks facing accounting firms have increased.

The Mode of Distribution of Benefits is Single Most accounting firms just think that the establishment of incentive mechanism is to give more care to employees from material conditions. However, in a short period of time, higher salaries can motivate employees. But in the long run, a reasonable incentive mechanism is indispensable for building a sound talent training mechanism. At present, the most common problem of accounting firms, accounting firms all income is limited, but the individual demand is diversified and personalized, so accounting firms ignore the occupation planning ability of staff training and staff correct, this leads to a contradiction between the interests and the interests of employees of certified public accountants. 


\section{Strengthen the Internal Governance of Accounting Firms in Our Country}

Improving the Internal Governance Mechanism. First of all, improve the management mechanism. Different accounting firms should take the different management system, and accounting firms should establish the board of directors and the board of supervisors, shareholders. For the audit work, the main content of the work of the internal audit work of accounting personnel is the supervision of internal control, but also bear the social identification. The enterprise wants to spend the least money getting the largest value and most satisfactory service. Secondly, the key to internal governance of China's accounting firms is to have a good leadership mechanism with good reform and good innovation. This is an open and democratic leadership mechanism. The firm should make collective and democratic decisions, and the decisions on major issues should be discussed together. At the same time, a multi stakeholder monitoring team should be established to supervise the implementation of the accountants, which will lead to higher standards of practice and higher quality of business.

Strengthen the Construction of Accounting Ethics. Accounting firms should strengthen the construction of accounting moral environment. CPA firms should create a social and moral environment related to each other, and they need to determine the corresponding morality. In this process, we should play a good role in the CPA profession association. In the occupation career, whether it is to help focus on training the employees working for, or for the occupation career planning partner, a member of the Institute of Certified Public Accountants always holds the tenet of service. It is also assists the accounting firm to strengthen the construction of accounting ethics. Therefore, in order to make the accounting firm healthy growth, we must cultivate the corresponding occupation moral guidance and establish the correct views.

Establishing a Proper Corporate Culture. Corporate culture has a guiding role. Excellent cultural values guide the specific behavior and attitudes of employees of enterprises to the positive side. The establishment of positive accounting firm culture will enable the firm to develop better and make employees' behavior more and more in line with the overall interests of the company. Specifically, the corporate culture can guide the members' thinking and behavior and guide the overall level of enterprise values. Enterprise culture must first let the employees feel valued. It can make staff identity firm concept by creating the appropriate corporate culture to guide the staff psychology to influence employee behavior. At the same time, to establish relevant articles of association, the construction of accounting firms and enterprise culture should also be clearly stated in the articles of association.

Establish a Perfect Risk Control System. First of all, all accountants should strengthen their awareness of the importance of risk, especially the risks in the process of business implementation. Secondly, the risk control of accounting firms should be systematic control. CPA firms should be cautious in selecting target customers, strengthening internal governance and improving audit methods. Finally, the accounting firm should be strict in internal governance activities. The Supervision Committee monitors should be strict and effectively control the responsibility of each project leader and emphasize the risk. The whole process can be carried out multi-level supervision and review to ensure higher quality of work.

\section{Establishing Diversified Distribution of Interests.}

It is the distribution of interests and power that is the essence and core of solving the problem of organizational governance mechanism. Only when the interests are properly solved can the firm achieve sustained and healthy development and provide higher quality services. The first is to establish a fair and just incentive mechanism and to implement effective performance appraisal system. Second, accounting firms should focus on dealing with issues related to wages,benefits, insurance and other interests, and develop a diversified distribution of benefits. Finally, the decentralized ownership structure should be constructed so that the general employees of accounting firms can participate in the distribution of surplus profits. 


\section{Conclusion}

To sum up, the internal prevention of accounting firms plays a very important role in helping us find problems and solve problems from the inside of the firm. Therefore, the perfect internal governance system and mechanism can ensure the quality audit of accounting firms. All aspects of accounting firms in China and the development of economic and social development is closely related to sharing. The accounting firms in our country should seize the opportunity, gradually strengthen internal management, and make efforts to improve the internal competitiveness of accounting firms.

\section{References}

[1] Huang Linlin, Zhang Limin. Specific system design of internal governance mechanism of CPA firms [J]. China CPA.2016:74-75

[2] Li Peng, Yang, Study on the issues of modern commerce industry.[J]internal control of accounting firms 2013:112-113

[3] $\mathrm{Wu} \mathrm{Xi.} \mathrm{CPA} \mathrm{firm} \mathrm{internal} \mathrm{governancetheory} \mathrm{principle} \mathrm{and} \mathrm{implications} \mathrm{for} \mathrm{development}$ strategies. [J]. auditing research,.2012. (3):76-82

[4] Huang Shenghua. Reflections on the internal governance of small and medium sized accounting firms.[J] North economics and trade. 2015:70-72

[5]ChenZifeng. The internal governance economy research of our accounting firms.[J].2016(19):87-89

[6] Wang Yong. Talking about internal governance construction of accounting firms [J]. financial supervision.2015:69-72

[7]Susan. China's accounting firm's internal governance mechanismof knowledge economy.[J]2017:74-77

[8] Gao Hong. Analysis of the reasons for brain drain and Countermeasures.[J].financial accounting window.2014:275-277 